\title{
Controle judicial na execução de políticas públicas ${ }^{1}$
}

\author{
Nahiane Ramalho de Mattos ${ }^{2}$ \\ Profa. Dra. Marlene Kempfer Bassoli ${ }^{3}$
}

\section{Resumo}

\begin{abstract}
Verifica a possibilidade da realização de um controle dos atos governamentais (políticas públicas) por parte do Poder Judiciário. Apresenta o conceito de políticas públicas. Relaciona políticas públicas com princípios administrativos. Define políticas públicas sociais. Apresenta os momentos (elaboração, execução, avaliação) em que pode ocorrer um eventual controle judicial. Foca-se no estudo da possibilidade de controle judicial na fase de execução de uma política pública. Relaciona posicionamentos contrários e favoráveis do exercício do controle judicial. Conclui que é possível esse controle do Poder Judiciário sobre os atos governamentais, desde que haja interdependência entre os Poderes e responsabilidade por parte do Judiciário.
\end{abstract}

Palavras-Chave: Políticas Públicas; Controle Judicial; Interesse Público; Execução.

\section{Introdução}

Diante do estudo sobre políticas públicas surgem dúvidas quanto às possibilidades e limites de controle por decisão judicial. Podem os cidadãos exigir judicialmente (e os juízes decidir sobre) a (não-) execução de programas políticos, atribuição do poder Executivo?

O controle judicial de políticas públicas é ainda pouco estudado pela doutrina. A análise deste tema remete a conceitos indeterminados de Direito Constitucional e Direito Administrativo, a questões conflitantes sobre discricionariedade e interesse público, como também a noções sobre Orçamento Público - este apenas apresentado, não discutido, pois não é o enfoque do estudo neste momento.

Para serem respondidas perguntas como aquela, tem-se que saber o que são políticas públicas, para o que elas se direcionam e qual o nexo com as atividades governamentais. Relacionando-se esses conceitos aos de democracia, direitos fundamentais

1 Este ensaio teve por referência Trabalho de Conclusão de Curso apresentado ao Curso de Direito da Universidade Estadual de Londrina, de autoria da primeira sob a orientação da segunda.

Aluna do 5ㅇ ano de Direito da Universidade Estadual de Londrina.

Doutora em Direito do Estado - Direito Tributário pela PUC-SP. Professora de Direito Tributário na graduação do Curso de Direito da Universidade Estadual de Londrina e dos programas de Mestrado em Direito da Universidade Estadual de Londrina e da Universidade de Marília. 
e justiça social, estuda-se a possibilidade de um eventual controle judicial, observando nas políticas públicas do Governo, qual a previsão legal desses instrumentos, quais os argumentos à atuação do magistrado e a limitação orçamentária para tal.

Assim, a partir do momento que tais políticas ocasionarem lesões à ordem constitucional, defende-se que o controle judicial será mecanismo apto a rever tais lesões, e, dessa forma, conservar os valores do Estado Democrático de Direito.

\section{Políticas públicas}

O particular tem direito de obter prestações através do Governo, pois cabe a este assegurar determinados direitos aos cidadãos, a exemplo de direitos fundamentais sociais, como saúde, educação, segurança pública. O Executivo não apenas executa as leis, ele cria suas próprias políticas e programas necessários à realização dos ordenamentos legais. (KRELL, 2002, p. 99). Esses direitos são viabilizados aos cidadãos através de políticas públicas.

Políticas públicas são instrumentos utilizados pelo governo para intervir na sociedade, na economia, na política, executando programas políticos em busca de melhores condições de vida aos seus cidadãos. São, para Dworkin (apud COMPARATO, 1997, p. 18), uma espécie de padrão de conduta (standard) que indica qual meta deve ser alcançada, para o que o governo deve se direcionar.

Não é outro o entendimento de Eduardo Áppio (2005, p. 136):

As políticas públicas podem ser conceituadas [...] como instrumentos de execução de programas políticos baseados na intervenção estatal na sociedade com a finalidade de assegurar igualdade de oportunidades aos cidadãos, tendo por escopo assegurar as condições materiais de uma existência digna a todos os cidadãos.

O autor evidencia que a finalidade da política pública é "assegurar igualdade de oportunidades aos cidadãos", isso quer dizer que deve-se buscar a "promoção da diminuição das desigualdades socioeconômicas", "garantir igualdade real de oportunidades através da atuação dos órgãos da Administração Pública" (ÁPPIO, 2005, p.145).

Tem-se que acrescentar outro valor às políticas públicas, que, com certeza é até mais importante que o anterior, qual seja, a obrigatoriedade das políticas públicas estarem diretamente voltadas a realizar os desígnios constitucionais. 
Explique-se melhor: esses programas de ação governamental têm de estar fundamentados em direitos previstos, ainda que de forma genérica, na Constituição.

Áppio (2005, p. 144), trazendo a idéia de Gouvêa, reporta que:

As políticas públicas consistem em instrumentos estatais de intervenção na economia e na vida privada, consoante limitações e imposições previstas na própria Constituição, visando assegurar as medidas necessárias para a consecução de seus objetivos, o que demanda uma combinação de vontade política e conhecimento técnico. (grifo nosso).

Maria Paula Bucci (2002, p. 254-255) aponta que o risco de interpenetrar direito e política é o de ser a lei descaracterizada pela lógica das políticas. E completa dizendo que "o modelo das políticas públicas não exclui o da legalidade, mas convive com ele", devendo ser as políticas públicas - ação ou omissão - reconhecidas pelo direito e gerar efeitos jurídicos.

Não se pode olvidar a diferenciação, pequena, mas importante, feita por Áppio, quanto à política pública social - a qual esse estudo se detém - e a política pública econômica. Para esse autor, no Brasil se desenvolvem esses dois tipos de políticas, "ambas com um sentido complementar e uma finalidade comum, qual seja, de impulsionar o desenvolvimento da Nação, através da melhoria das condições gerais de vida de todos os cidadãos". (ÁPPIO, 2005, p. 136)

Contudo a primeira se caracteriza pela distribuição de bens sociais fundamentais por parte dos governos eleitos, como educação e saúde pública, enquanto a segunda ocorre pela intervenção estatal na economia privada. (ÁPPIO, 2005, p. 136)

Destarte, políticas públicas sociais "simbolizam [...] a pretensão de planejamento social a partir da execução de projetos governamentais" (ÁPPIO, 2005, p. 136) que obedeçam a direitos previstos na Constituição e tenham por fim a conservação do principio da isonomia.

Outra característica das políticas públicas que deve ser analisada diz respeito à relação entre esta e a discricionariedade, pois, segundo Bercovici (2003, p. 302) em parágrafo explicativo de Bucci, "o que há em comum em todas as políticas públicas é o processo político de escolha de prioridades para o governo, tanto em termos de finalidades como em termos de procedimentos". 
Entretanto, a possibilidade de se exigir o cumprimento de uma política pública em juízo não se dá apenas quando se trata de poder discricionário, pelo contrário, a busca por controle pode ocorrer em diferentes momentos.

Passa-se, assim, a analisar a possibilidade de controle judicial de políticas públicas sociais, e a observar a influência dos magistrados na condução dessas políticas.

\section{Controle judicial de políticas públicas}

Após entender o que são políticas públicas, percebe-se, segundo Comparato, (1997, p. 17) que "a legitimidade do Estado [...] não está na expressão legislativa de soberania popular, mas na realização de finalidades coletivas".

A busca por metas predeterminadas não pode ser usada de modo "arbitral" por nenhum dos poderes do Estado (aqui tratando especificamente do Executivo) deixando que o significado de discricionariedade oscile conforme melhor convier ao Administrador. Há que se lembrar que essa "realização de finalidades coletivas" remete ao conceito de interesse público - conceito outrora explicado, mas que não é demais frisar ser o que se inclina em provento do público, da sociedade, e não à vontade de grupos particulares.

O interesse público deve ser analisado através de sua indisponibilidade e a Administração não pode se afastar deste em momento algum. Ela possui uma margem de atuação de "conveniência e oportunidade", mas essa margem está intimamente ligada, melhor seria dizer, subordinada aos valores desse Estado de Direito. Assim, para assegurar que a política governamental estará revestida de finalidade coletiva, interesse público, valores do Estado de Direito, é que se defende a possibilidade de um controle desses atos pelo Poder Judiciário. O que pode ocorrer em três momentos distintos.

O controle judicial das políticas públicas pode ser preventivo, quando de sua formulação, momento em que são apresentados os "pressupostos técnicos e materiais, pela Administração ou pelos interessados, para confronto com outros pressupostos, de mesma natureza, trazidos pelas demais partes, cujos interesses sejam não-coincidentes com aqueles" (BUCCl, 2002, p. 266), Nessa fase, a participação popular - seja através de conselhos deliberativos, envolvimento social - apresenta grande relevância. Pode ser concomitante, quando da execução, implementação do programa. Como também pode ser posterior, quando da avaliação, fase em que se observam os efeitos sociais e jurídicos 62 
decorrentes da política já implementada, se observa a obediência ao princípio da legalidade e de legitimidade - momento este em que a doutrina se apresenta pacífica quanto à possibilidade, para não dizer obrigatoriedade, de controle.

O controle na fase de execução das políticas públicas será aqui aprofundado, já que não é suficiente o Estado "prometer" que agirá (seja por norma constitucional, políticas públicas ou outro meio), se não houver realização prática, através de mecanismos para efetivar tais garantias. (GALILHETI, 2001, p. 33).

\subsection{0 exercício do controle judicial}

O controle judicial se justifica não só pelo princípio basilar de que todos têm direito ao acesso à justiça, mas também por outros princípios, quais sejam, a garantia de atuação do Poder Judiciário como sujeito (não como parte, e sim segundo agente do Estado) da relação processual de conflito em busca de verdade real; o princípio da isonomia entre os cidadãos; os princípios constitucionais administrativos, dentre outros, aqueles dispostos no artigo 37, caput, da Constituição Federal:

A administração pública direta e indireta de qualquer dos Poderes da União, dos Estados, do Distrito Federal e dos Municípios obedecerá aos princípios de legalidade, impessoalidade, moralidade, publicidade e eficiência. (grifo nosso)

Assim, deveria ser pacífico que o controle é instrumento necessário para se compatibilizar os programas de ação do governo com as regras postas pela Constituição e pelas leis.

Não é outro o entendimento de Comparato ao sugerir que "afastemos, antes de mais nada, a clássica objeção de que o Judiciário não tem competência, pelo princípio da divisão de Poderes, para julgar 'questões políticas'”. Explica que esse entendimento negativo teve origem na Constituição de 1934 que vedava "ao Poder Judiciário conhecer de questões exclusivamente políticas" (art. 68 CF/34). Mas diz que essa clássica falsa objeção de muito já está esclarecida, pois se tratava apenas de uma hermenêutica pobre, quando, na verdade, o que se queria vedar era o controle judicial sob questões "de política" (lato sensu) (COMPARATO, 1997, p. 19-20). 
Contudo, os operadores do Poder Público, nos três Poderes, ao longo da história e ainda hoje, não entendem (ou não querem entender) esse real significado, seja porque não querem que haja outro agente criador do direito (legislativo), seja porque não querem ter suas atividades controladas (executivo), ou porque não querem assumir responsabilidades (judiciário).

Não deveria ser assim. Se a finalidade da ação do Poder Público é defender o interesse público, ora, tanto o Executivo, o Legislativo, quanto o Judiciário são componentes desse Poder e, ao invés de sustentarem uma "divisão dos Poderes", deveriam identificar, juntos, o interesse público mais relevante na questão.

Cappelletti (apud OLIVO, 2001, p. 24) é claro ao dizer da necessidade de "coexistir um legislativo forte com um executivo forte e um judiciário forte". Não se espera que o Judiciário domine os demais Poderes. Não há submissão entre eles. Contudo, ao longo da história, o Judiciário se tornou "débil e confinado, em essência, aos conflitos individuais" e agora vem ressurgindo. O Judiciário não pode mais se ater, apenas e simplesmente, a julgar conforme determinou o legislador ou conforme previu o administrador público. Deve haver interpenetração entre os poderes, pois, só através dessa igualdade de atuação, o bem-estar social será alcançado.

Dever-se-ia, de fato, entender ser falsa a "objeção à judiciabilidade das políticas governamentais". Nesse sentido, OLIVO (2001, p. 23), explica que o Estado moderno (BemEstar Social) assume cada vez mais compromissos e intervém na vida social, necessitando, para isso, de uma forte produção legislativa e de uma máquina administrativa e burocrática, ampla o suficiente, para realizar tais tarefas, como também de mudança no comportamento dos juízes.

Pode-se ainda citar outro exemplo da objeção ao controle jurisdicional. O judiciário brasileiro vive um aparente constrangimento - se assim pode-se chamar - ante as novas situações derivadas de ações ou omissões do Poder Executivo que lhe têm sido apresentadas e, dessa forma, se escusam de uma intervenção. Isso significa, para José Eduardo Faria (apud KRELL, 2002, p. 74), que os magistrados têm "desprezado o desafio de preencher o fosso entre o sistema jurídico vigente e as condições reais da sociedade, em nome da 'segurança jurídica' e de uma visão por vezes ingênua do equilíbrio entre os poderes autônomos". 
Não se deve pensar que a não-intervenção judicial nessas hipóteses é devido à "inocência" do magistrado. Esse "desinteresse" decorre do receio de ser cobrado por seus atos. Qualquer aumento na despesa orçamentária precisa ter expressa previsão em Plano Plurianual, Lei de Diretrizes Orçamentária, Lei Orçamentária Anual, e, se desrespeitar essas formalidades, o juiz será responsabilizado (inclusive pessoalmente) por uma possível convulsão financeira nos orçamentos públicos. Assim, quando se trata de orçamento público, a Constituição parece tornar-se menos social, e isso acarreta uma real limitação à intervenção.

Vê-se, a partir disso que a problemática jurídica sobre o controle judicial das políticas públicas ainda está longe do fim. O controle judicial, no entendimento de Eduardo Áppio (2005, p. 167-174), só é aceitável quando se observa ao que cada política pública está relacionada, como está disposta no texto legal, como o Executivo se posiciona a respeito. Ele defende que a intervenção positiva do Poder Judiciário (sobre o Poder Executivo) se revela como excepcional e vinculada aos casos previstos na Constituição. Aponta, também, que só cabe revisão judicial no sentido de controle da execução das políticas públicas nos casos em que não exista uma prerrogativa constitucional erigida em favor do Poder Executivo. E passa a apresentar as seguintes (não-) possibilidades de intervenção.

Quanto aos programas sociais não previstos na Constituição Federal ou posto de forma genérica e, aqueles não previstos em lei, diz que ao judiciário não cabe intervir por sentença em Ação Civil Pública, pois os governantes eleitos têm discricionariedade para executar as políticas públicas mais adequadas ao seu programa de governo, até mesmo estendendo a pauta mínima dada pela Constituição. Aceita, entretanto, que se promova Ação Civil Pública no sentido de vincular o Executivo, nos casos em que já houver ocorrido deliberação acerca de determinada política em instâncias de democracia participativa.

Outro caso, e este com resultado diverso ao anteriormente analisado, é o que diz respeito à política social prevista de modo específico na Constituição. Aqui, o Executivo tem o dever de cumprir, se não o fizer, compete ao Judiciário exercer o controle através de Ação Civil Pública. Para esse tipo de política social, há fonte de financiamento prevista na Constituição, através de repasses obrigatórios, ou, mesmo nos casos em que não existam valores específicos previstos em orçamento, a ordem judicial determinará o uso de recurso previsto em rubrica especial destinada às despesas emergenciais. 
Se, todavia, a política social estiver prevista em lei, significa que o legislador previu a implementação de um programa social de modo genérico e abstrato e incumbiu ao Executivo a execução deste na forma da lei, segundo os limites da Lei Orçamentária anual. Essa previsão legal vincula a Administração Pública que, se for omissa, sofrerá controle judicial.

Pode ocorrer ainda, conforme Áppio, a busca por proteção aos direitos fundamentais. Nesses casos, ele entende que o juiz não pode determinar a implementação de uma política pública para atender as necessidades individuais, e, se o fizer, estará afrontando o princípio da isonomia. Mas, se já houver política implementada, o direito do cidadão deve ser protegido, podendo assegurá-lo mesmo através de ação individual.

Contudo, tal pensamento não pode prosperar, posto que os direitos fundamentais estão previstos no texto constitucional. A Constituição Federal não pode ser um texto ilustrativo, tem que ser vivenciada em sua plenitude. Assim, os direitos fundamentais vinculam a todos os poderes não só pela obrigatoriedade do Estado de nãofazer intervenções em áreas protegidas pelos direitos fundamentais, mas também de fazer tudo para sua realização.

Como se vê, mesmo no que se refere à execução, não são pacíficas as possibilidades de controle. No entanto, a evolução exigirá, cada vez mais, a influência do Poder Judiciário na implementação de políticas públicas e, só assim, chegar-se-á mais próximo do real conceito de justiça social.

Deve-se tratar, ainda, como o magistrado, sua atuação, os mecanismos de que dispõe influem (a favor ou contra) o exercício do controle judicial sob as políticas públicas sociais.

O fato de os juízes não serem eleitos, através de sufrágio universal, significa para Áppio, que eles não possuem legitimidade democrática como o Executivo e o Legislativo a possuem.

Contudo, é através da atuação dos juízes, da possibilidade de acesso ao processo judicial, que muitos excluídos realizam suas pretensões e, assim, exercem efetiva participação popular, o que dificilmente ocorre junto à Administração e ao Legislativo devido à centralização. 
O Judiciário, também, não possui mecanismos para identificar as reais necessidades sociais, tendo que recorrer a dados fornecidos pelo próprio Executivo. Entretanto há de se observar que o que se espera, através do controle judicial, não é que o juiz exerça o papel de Administrador, e sim que proporcione efetividade às garantias e programas sociais. Para tanto, o juiz não pode estar sozinho, tudo deve fazer parte de um programa no qual o juiz seja um dos atuantes.

Outro argumento contrário ao controle é o de que a Administração é autônoma, possui discricionariedade e que os juízes não sabem interpretar conceitos indeterminados. Desse assunto, outrora exaurido, concluiu-se, devido ao inegável interesse público, que não se admite dizer que políticas públicas são atividades puramente discricionárias. Necessita-se de um Poder Judiciário intervencionista, que controle a falta de qualidade das prestações dos serviços básicos e exija a implementação de políticas sociais eficientes. (KRELL, 2002, p. 97)

Frise-se que a finalidade do controle não é invadir o domínio dos demais Poderes, não é tornar juiz em legislador ou administrador, nem convertê-lo em Poder Político. No entanto, também não pode ficar "apolitizado", cego diante de leis e ações/omissões notadamente injustas. (GALILHETI, p. 32). Assim, o que se anseia não é que o Judiciário se torne um super poder, um ditador, ou burocrata. Ele deve ter compromisso com a justiça normativa constitucional, neutralizando as "conveniências políticas" do administrador, mas não se eximindo do dever de motivar seu próprio convencimento.

Além disso, toda vez que o juiz criar ou decidir de forma inaceitável, poderia-se recorrer, conforme Cappelletti (apud OLIVO, 2001, p. 25-26), a um sistema de controle recíproco, no qual tal sentença judicial seria corrigida mediante ato do Legislativo e Executivo, isto é, o Judiciário não estaria imune a uma revisão por parte dos demais Poderes.

Logicamente, quando Cappellletti tratou de tal controle recíproco, ele se baseava em um sistema diferente do brasileiro. Entretanto, se estendido à realidade deste país, percebesse que um controle externo dos atos do judiciário tem se levantado. É o denominado Conselho Nacional de Justiça.

É verdade que ainda se manifesta de forma embrionária, mas dentre suas funções, pode-se destacar a de receber reclamações contra membros ou órgãos do Judiciário, 
inclusive contra seus serviços auxiliares, serventias e órgãos prestadores de serviços notariais e de registro que atuem por delegação do poder público ou oficializados.

O Judiciário sofre, ainda, devido à falta de mecanismos que garantam o cumprimento das sentenças.

Nesse sentido, Andreas Krell (2002, p. 85) chama atenção:

Em princípio, a estrutura do Poder Judiciário é relativamente inadequada para dispor sobre recursos ou planejar políticas públicas. O Terceiro Poder carece de meios compulsórios para a execução de sentenças que condenam o Estado a cumprir uma tarefa ou efetuar uma prestação omitida; não há meios jurídicos para constranger o legislador [administrador] a cumprir a obrigação de legislar [administrar].

Talvez esse seja um ponto para o qual não se consiga apresentar soluções, pois não se sabe ao certo quando as sentenças terão real efetividade, já que não dependem apenas de fatores judiciais, mas também de fatores jurídicos, sociais, políticos e econômicos.

Se, no entanto, a garantia do cumprimento das sentenças torna-se difícil, surgem, cada vez mais, meios processuais que garantem o acesso ao controle jurisdicional, agora não mais apenas através de ação civil pública, e sim por ação coletiva, mandado de injunção, ação direta de inconstitucionalidade, ação declaratória de inconstitucionalidade, ação de inconstitucionalidade por omissão, argüição de descumprimento de preceito fundamental. Esses remédios processuais ainda não têm sido aproveitados em sua potencialidade, mas isso por serem instrumentos novos, frutos dessa evolução.

O Executivo tende a criar uma barreira de cunho prático ao controle judicial no que diz respeito à indicação da fonte dos recursos quando o juiz prolata uma decisão no sentido de vincular o Poder Público.

Se, ao tratar da falta de efetividade do cumprimento das sentenças diz-se que é um ponto sem aparente solução, imagine quando a discussão é estendida à questão orçamentária.

A formulação e execução de políticas públicas devem obedecer aos limites de receita e despesa. Todas as despesas do Governo (Entes Federados) devem ser previstas em Lei Orçamentária Anual encaminhada pelo Executivo e votada pelo Legislativo, condizente à Lei de Diretrizes Orçamentárias, que, por sua vez, precisa estar em conformidade com a Lei de Responsabilidade Fiscal. 
O Executivo, ao formular uma política pública, deve analisar se possui recurso suficiente para tal e, desde aquele momento, prever essa despesa em Lei Orçamentária Anual. Não é diferente a atuação do Judiciário que, ao sentenciar, deve indicar de que parte do orçamento será tirado o valor para essa nova despesa.

Destarte, a questão orçamentária é um grande problema, se não o maior, para efetividade do controle judicial e, infelizmente, não possui nem previsão de quando será resolvida. Entretanto, não é possível também, ignorar direitos sociais dos cidadãos.

Se a coexistência entre direitos sociais e disposição orçamentária for aceita - e é isso que se anseia, não há outra alternativa além de se permitir que o juiz possua liberdade para agir, politicamente, corrigindo as injustiças da norma e do desinteresse do Administrador, contudo, com responsabilidade. (GALILHETI, 2001, p.35)

\section{Conclusão}

A história demonstra claras tentativas do Poder de sobrepor-se ao Direito. A teoria da separação dos poderes, que deveria ser garantia contra o arbítrio dos Poderes, tornou-se mecanismo para facilitá-lo. O Judiciário não tinha espaço e, por isso, ateve-se basicamente a julgar conflitos individuais, enquanto que o Executivo e o Legislativo impunham, sobre as maiorias "pobres", a vontade de particulares, a vontade de minorias "nobres", e sem sofrer controle algum por essas atitudes.

Não é porque o Legislativo tem a função de fazer as leis que a todos vinculam e porque o Executivo goza de certa discricionariedade que eles não observarão e obedecerão ao princípio de primazia do interesse público sob o particular.

Diante disso, se as ações/omissões do Executivo (aqui focado apenas a atuação deste poder) forem instrumentos para executar programas governamentais, devem ser direcionadas à melhoria dos cidadãos. Se, todavia, tal pressuposto não for observado, conclui-se este estudo na defesa da intervenção judicial sobre as políticas públicas, desde que, o juiz não esteja sozinho, aja com responsabilidade e responda por seus atos.

Por essas dificuldades à intervenção judicial, é que Comparato considera "remota" a probabilidade de introdução do controle no país. Entretanto, não podem os obstáculos nortear a esperança e os anseios populares, pois, como este autor completa, "a democracia nunca é [foi] o fruto de uma evolução natural e inelutável da sociedade humana, [...] [mas 
sim um longo] e penoso trabalho de defesa da dignidade humana". (COMPARATO, 1997, p. 22)

\section{Referências}

ÁPPIO, E. Controle Judicial das Políticas Públicas no Brasil. Curitiba: Juruá, 2005.

BERCOVIC, G. Desigualdades Regionais, Estado e Constituição. São Paulo: Max Limonad, 2003.

BOBBIO, N.; MATTEUCCI, N.; PASQUINO, G. Dicionário de Política. 2 ed., Brasília: Universidade Brasília, 1986.

BOBBIO, N. Teoria do Ordenamento Jurídico. Brasília: UNB, 1999.

BONAVIDES, P. Do Estado Liberal ao Estado Social. 2 tir. 7. ed. São Paulo: Malheiros, 2004. . Teoria do Estado. 4 ed. São Paulo: Malheiros, 2003.

BUCCl, M. P. D. Direito Administrativo e Políticas Públicas. São Paulo: Saraiva, 2002.

COMPARATO, F. K. Ensaio sobre o juízo de constitucionalidade de políticas públicas. Revista dos Tribunais, ano 86, v.737, p. 11-12, mar. 1997.

DALLARI, D. A. Elemento de Teoria Geral do Estado. 24 ed. São Paulo: Saraiva, 2003.

GALILHETI, E. J. A produção do direito fora da esfera Legislativa - O judiciário como agente criador do direito positivo. Revista ciêntífica UNOESC, Joaçaba, v.2, n.2, p. 29-50, 2001.

KRELL, A. J. Direitos Sociais e Controle Judicial no Brasil e na Alemanha: Os (des) caminhos de um direito constitucional "comparado". Porto Alegre: Sergio Antonio Fabris, 2002.

MEIRELLES, H. L. Direito Administrativo Brasileiro. 29. ed. São Paulo: Malheiros, 2004.

MORAES, G. de O. Controle Jurisdicional da Administração Pública. 2. ed. São Paulo: Dialética, 2004.

MÜLLER, M. S.; CORNELSEN, J. M. Normas e Padrões para Teses, Dissertações e Monografias. 5 ed., Londrina: Eduel, 2003. 
OLIVO, L. C. C. de. Juízes Legisladores: O controle de Constitucionalidade das Leis como forma de exercício do poder judiciário. Revista jurídica/Faculdade Novo Ateneu, Guarapuava, v.1, n. 1, p. 17-33, 2001.

STRECK, L. L. Hermenêutica jurídica e $(m)$ crise: Uma exploração hermenêutica da construção do Direito. Porto Alegre: Livraria do Advogado, 2003.

Jurisdição Constitucional e Hermenêutica: Uma Nova Crítica do Direito. 2. ed. Rio de Janeiro: Forense, 2004.

STRECK, L. L.; MORAIS, J. L. B. Ciência Política e Teoria Geral do Estado. 4. ed. Porto Alegre: Livraria do Advogado, 2004 
